years) had higher burnout scores than their more experienced colleagues ( $>10$ years).

Discussion This is the first Irish study investigating midwives' experiences of burnout and possible contributory workplace factors. Midwifery profession demand a high degree of empathy. Our principal results highlight the significant effects of personal responses to distressing work events. Further research looking at workplace supports is recommended.

\section{ASSOCIATION BETWEEN EMOTIONAL SYMPTOMS AND JOB DEMANDS IN THE ELECTRONICS FACTORY}

${ }^{1,2} \mathrm{PC} C \mathrm{Chu}^{*}, 1,3,4 \mathrm{YL}$ Guo, ${ }^{1,3} \mathrm{PC}$ Chen, ${ }^{5} \mathrm{LW} \mathrm{Liu},{ }^{5} \mathrm{CY}$ Chen. ${ }^{1}$ Department of Environmental and Occupational Medicine, National Taiwan University and National Taiwan University Hospital, Taipei, Taiwan; ${ }^{2}$ Department of Environmental and Occupational Medicine, National Taiwan University Hospital Hsin-Chu Branch, Hsinchu, Taiwan; ${ }^{3}$ Institute of Occupational Medicine and Industrial Hygiene, College of Public Health, National Taiwan University, Taipei, Taiwan; ${ }^{4}$ National Institute of Environmental Health Sciences, National Health Research Institutes, Zhunan, Taiwan; ${ }^{5}$ Institute of Labour, Occupational Safety and Health, Ministry of Labour, New Taipei City, Taiwan

\subsection{6/oemed-2018-ICOHabstracts.1709}

Introduction Emotional symptoms are related to work-related factors. The understanding of the association between emotional symptoms and job demands in the electronics industry is limited. The objective was to examine the relationships between emotional symptoms and job demands.

Methods We conducted a cross-sectional study, which enrolled 458 workers in the electronics factory. Personal factors, workrelated factors, and emotional symptoms were assessed by the self-administered questionnaire. Emotional symptoms were comprised of depressive and hostility. The job demands included the following items: working under high pressure, working hours, workload, imbalance between job demands and workers' abilities, monotonous job, physical risks, unclear understanding about job duties, conflicting demands, and socially isolation at work. Multiple logistic regression analysis was applied to explore the association between work-related factors and emotional symptoms.

Results Among the study population, 154 (33.6\%) had emotional symptoms. In the simple logistic regression analysis, regular exercise $(\mathrm{OR}=0.46)$, working under high pressure $(\mathrm{OR}=3.05)$, working long hours $(\mathrm{OR}=2.42)$, high workload $(\mathrm{OR}=2.31)$, imbalance between physical and mental job $(\mathrm{OR}=1.73)$, conflicting demands $(\mathrm{OR}=3.94)$, and social isolation at work $(\mathrm{OR}=4.89)$ were significantly related to the presence of any symptom of depression or hostility. Further, in the multiple logistic regression model adjusted for other variables, regular exercise $(\mathrm{OR}=0.51,95 \% \mathrm{CI}: 0.30$ to 0.88$)$, working under high pressure $(\mathrm{OR}=1.84,95 \% \mathrm{CI}: 1.05$ to $3.21)$, conflicting demands ( $\mathrm{OR}=2.15,95 \% \mathrm{CI}: 1.30$ to 3.57$)$, and social isolation at work $(\mathrm{OR}=2.9,95 \% \mathrm{CI}: 1.23$ to 7.30$)$ were significantly related to the presence of any symptom of depression or hostility.

Conclusions Working under high pressure, conflicting demands, and social isolation at work may be the risk factors for emotional symptoms. Therefore, workplace mental health promotion should focus on not only education of lifestyle modifications (i.e. exercise), but also job demands.
656 MENTAL HEALTH AND QUALITY OF LIFE ARE STRONGLY ASSOCIATED TO OCCUPATIONAL STRESS: A STUDY WITH WORKERS FROM A YOUTH CUSTODY CENTRE IN BRAZIL

${ }^{1}$ Fernando Feijo, ${ }^{3}$ Cristiane Bunchen, ${ }^{2}$ Inaiara Kersting, ${ }^{2}$ Paulo Antonio Oliveira. ${ }^{1}$ Federal University Of Pelotas, Pelotas, Rio Grande do Sul, Brazil; ${ }^{2}$ Federal University of Rio Grande do Sul, Porto Alegre, Rio Grande do Sul, Brazil; ${ }^{3}$ Federal University of Health Sciences, Porto Alegre, Rio Grande do Sul, Brazil

\subsection{6/oemed-2018-ICOHabstracts. 1710}

Introduction Workers from Youth Custody Centres are submitted to several occupational stressors in Brazil. Therefore, we aimed to investigate the impact of occupational stress in mental health and quality of life of workers from a youth custody centre.

Methods Cross-sectional study with a sample of 208 civil servants from a youth custody centre in southern Brazil. We used the Job Stress Scale (JSS) to analyse the exposure to psychological demands, job control and social support at work, based on the job strain model. Outcomes were measured using the Beck Anxiety Inventory (BAI), the Beck Depression Inventory II (BDI-II) and the World Health Organisation Quality of Life instrument - brief version (WHOQOL-bref) to evaluate anxiety, depression and quality of life of workers.

Results Physical, social relationships and environmental domains of quality of life had low mean scores in our sample. Job strain was associated with lower scores in all quality of life domains. Psychological demands and low social support were strongly associated to worse scores in quality of life. Anxiety and depression were also strongly associated to worse quality of life.

Discussion Occupational stress and bad mental health are associated to worse scores in quality of life in these workers.

\section{KAROSHI SYNDROME AND VIOLENCE: EXTREME LABOUR STRESS ASSOCIATED TO DEATH BY ACUTE CARDIOVASCULAR EVENT. A CASE REPORT}

P Garza* , A Ureña. Mexican Social Security Institute, Acapulco, Mexico

\subsection{6/oemed-2018-ICOHabstracts.1711}

Introduction Karoshi, is the result of extreme work related stress by an excess of work, presenting acute cardiovascular episodes such as the cerebrovascular disease.

Methods A case report.

Results Male 46 years old, no important family history. Smoking and alcoholism denied, diagnosed with hypertension 5 years ago, keep it stable. He is a company manager. On 07/ $30 / 2009$, when he was in his work area, he received an extortion call because he was the company's manager, he later reported to the corresponding authorities, without having any preventive action or response against it. Afterwards, because of the social and economic situation of the state, the company felt obligated to reduce the amount of workers in a very impactful manner, by which the employee starts to supply the needs of other areas in addition to his own, registering more than 20 extra activities, added to the increase of his workday hours. In 2011, he presented affective flattening, irritability, insomnia, headaches, chest pain, lower back pain, and anxiety, 